\title{
Low Base Rates and a High IQ Selection Threshold Prevented Terman from Identifying Future Nobelists
}

\author{
Russell T. Warne ${ }^{1}$, Ross A. A. Larsen ${ }^{2}$, and Jonathan Clark ${ }^{2}$ \\ ${ }^{1}$ Department of Behavioral Science, Utah Valley University \\ ${ }^{2}$ Department of Instructional Psychology \& Technology, Brigham Young University
}

\section{Published article! Please cite as:}

Warne, R. T., Larsen, R. A. A., \& Clark, J. (2020). Low base rates and a high IQ selection threshold prevented Terman from identifying future Nobelists. Intelligence, 82, Article 101488. https://doi.org/10.1016/j.intell.2020.101488

\section{Author Note}

Russell T. Warne (D) https://orcid.org/0000-0003-4763-3625

Ross A. A. Larsen (D https://orcid.org/0000-0002-5924-3993

We have no conflicts of interest to disclose.

Correspondence concerning this article should be addressed to Russell T. Warne, $800 \mathrm{~W}$. University Parkway MC 115, Orem, UT 84058. Email: rwarne@uvu.edu 


\begin{abstract}
Although the accomplishments of the 1,528 subjects of the Genetic Studies of Genius are impressive, they do not represent the pinnacle of human achievement. Since the early 1990s, commentators have criticized the study because two future Nobelists - William Shockley and Luis Alvarez-were among the candidates screened for the study; but they were rejected because their IQ scores were too low. Critics see this as a flaw of Terman's methodology and/or intelligence testing. This study simulates the Terman's sampling procedure to estimate the probability that Terman would have selected one or both future Nobelists from a population of 168,000 candidates. Using simulations, we created a model that reflected the reliability of the IQ scores used to select individuals for the Genetic Studies of Genius and the relationship between IQ and Nobelist status. Results showed that it was unlikely for Terman to identify children who would later earn Nobel prizes, mostly because of the low base rate of earning a Nobel and the high minimum IQ needed to be selected for Terman's study. Changes to the methodology that would have been required to select one or both Nobelists were not practical. Therefore, future Nobelists' absence from the Genetic Studies of Genius sample is not a fatal flaw of intelligence testing or Terman's study. Instead, predicting high levels of eminence requires measuring a variety of relevant cognitive and non-cognitive variables. A preprint version of this paper is available at https://psyarxiv.com/g4x6r/. Simulation code and results and reliability generalization information are available at https://osf.io/3xfe8/.
\end{abstract}


Low Base Rates and a High IQ Selection Threshold Prevented Terman from Identifying Future Nobelists

Lewis Terman's landmark longitudinal study of 1,528 high-IQ children, the Genetic Studies of Genius, is one of the most important studies in the history of psychology. It was one of the first longitudinal studies, and it provided strong evidence for the validity of intelligence test scores as predictors of academic and non-academic life outcomes (Warne, 2019). The data from the study still continue to produce findings that are published in scholarly journals (e.g., Gensowski, 2018; Martin et al., 2007; Warne \& Liu, 2017). In the years since the study began, a consensus has formed that it is an impressive project that advanced knowledge in psychology and education (Friedman \& Martin, 2011; Greenberg, 1955; Minton, 1988; Warne, 2019; Winkler \& Jolly, 2014). The Genetic Studies of Genius was vitally important in providing evidence that IQ scores were correlated both with success in the schoolhouse and with life outcomes in adulthood. Evidence that intelligence matters wields an influence in many-if not all—aspects of life as accumulated since then and now forms a massive body of research (see Lubinski, 2004, for a review).

However, many have been critical about aspects of the Genetic Studies of Genius. One common criticism is the lack of a control group of typical children to compare to the 1,528 gifted children Terman selected (Stanley, 1974). Commentators have also found fault with the low racial diversity in the sample (95-99\% White) and the disproportionate number of sample members raised in middle- and upper-class homes (Minton, 1988; Robinson, 1981; Sorokin, 1956). Terman also meddled in the lives of the children in his study (Shurkin, 1992), which undermines the generalizations that can be made regarding the relationship between intelligence 
and life success. Cohort effects also threaten the generalizability of the study, with some psychologists questioning how much data from a sample of people with an average birth year of 1910 can generalize to modern gifted children (Holahan \& Sears, 1995; Rinn \& Bishop, 2015; Warne \& Liu, 2017). The degree to which these criticisms threaten the quality of the study varies (see Warne, 2019, for a nuanced discussion), but they do not change the monumental accomplishment that it was to collect data semi-regularly throughout the lifespan from a large sample of people.

In recent decades, one fact about the study has made some question the validity of intelligence as a measure of "genius" and/or the study's premise as a whole. Of the 168,000 children that Terman's team screened and evaluated in preparation for the study, two children that were not selected later won Nobel Prizes in physics as adults: William Shockley and Luis Alvarez. This claim was first made in print by William Shockley himself in an interview conducted by journalist Syl Jones (1980, p. 76). On the basis of interviews of Shockley and Alvarez, Shurkin (1992, p. 35) repeated this information in his book about the Terman longitudinal study. Shurkin $(2006$, pp. 13, 216) provided more detail in his biography of Shockley, where he stated that Shockley took intelligence tests twice in his childhood—scoring 129 the first time and 125 the second time - and once in adulthood, scoring at the 90th percentile - the equivalent of an IQ of 119. Alvarez's exact IQ score is apparently not public, but it also was too low for inclusion in Terman's longitudinal study. Their scores were apparently typical among science Nobelists: Root-Bernstein (2015) reported IQs in the 120s for James Watson and Richard Feynman.

In recent years, the failure to identify Alvarez and Shockley as gifted has been perceived as a flaw in either the Genetic Studies of Genius or intelligence testing (e.g., Heilman, 2016; 
Rubenstein et al., 2013). For example, Simonton (2015) saw Shockley and Alvarez's absence from Terman's study as evidence that intelligence tests were ineffective at predicting creative accomplishments, while Bond (2014) believed that the omission of Alvarez and Shockley in the Genetic Studies of Genius as a consequence of Terman's flawed overemphasis on IQ. Shockley and Alvarez's rejection from the Genetic Studies of Genius reached a widespread audience when Malcolm Gladwell (2008, p. 90) discussed it in his bestselling book Outliers as evidence that Terman's study was fatally flawed and that “... Terman didn't understand what a real outlier was" (Gladwell, 2008, p. 77).

While not disputing the facts, Warne (2019) presented a contrasting view based on actuarial methods of selecting individuals. Predictions of success for any selected groupwhether "success" is defined as satisfactory job performance or achieving eminence through a Nobel prize - is dependent on three characteristics: the proportion of population members who will meet the definition of success, the proportion of individuals selected from the population, and the correlation between the two selection variable and the success criterion (Dawis, 1996). Over 80 years ago, Taylor and Russell (1939) showed mathematically that when success is only achieved by a small proportion of the population, then the probability of selecting a successful candidate is below .50 , unless the correlation between the selection variable and the success criterion is very high. For example, when only $5 \%$ of the population would be successful at an endeavor, then the probability that a person selected on a screening measure would be successful on the criterion variable is only .11 if the correlation between the two variables is $r=.20$. Even with a moderate correlation of $r=.50$, the probability of success among selected individuals is still only .24 . The probability of success does not reach .50 until the correlation is $r=.80$ (Taylor 
\& Russell, 1939). Thus, for situations where "success" has a low base rate, most selected individuals will likely not be successful.

Warne (2019, p. 16) applied this information to selecting Nobel Prize winners from the population, arguing that “... outcomes with low base rates are extremely difficult to predict.” He stated that selecting both Alvarez and Shockley for the Genetic Studies of Genius would have been unlikely unless (a) Terman's minimum cutoff score for selection into the longitudinal study were equal to or lower than Nobel Prize winners' minimum IQ scores, (b) the intelligence test scores had high very reliability, and (c) there was a high correlation between IQ and winning a Nobel Prize. Warne (2019, p. 16) concluded, “There is no evidence that all three of these requirements were present at the time Terman was selecting children for participation in Genetic Studies of Genius.”

However, Warne (2019) presented no data supporting this assertion. The purpose of this study is to examine Warne's defense of Terman and to estimate realistic probabilities that one or both future Nobel Prize winners in the population of California school children that Terman's team screened would be selected for inclusion in the Genetic Studies of Genius. We will use simulated data based on the conditions that were likely present when Terman conducted the study. Therefore, our specific research questions are as follows:

1. Given known characteristics of Terman's sampling method and the population, what is the estimated probability of Terman's sampling method selecting one or both future Nobelists?

2. Which characteristics of the sampling selection procedure (i.e., minimum IQ necessary for earning a Nobel, correlation between IQ and earning a Nobel Prize, and amount of measurement error) are most influential in identifying future Nobelists? 


\section{Terman's Sampling Method}

In order to answer the research questions and to determine plausible simulation conditions, it is necessary to understand how children in the 1920 s were identified for the Genetic Studies of Genius. The sampling method that Terman used to select his individuals for his longitudinal study was complicated. In Volumes I, III, and IV of the Genetic Studies of Genius (Burks et al., 1930, p. 15; Terman, 1926, p. 39; Terman \& Oden, 1947, p. 7), the sample size and the composition of the sample shifts slightly. The initial sample (in 1921-1922) consisted of 1,444 individuals, but by 1927-1928, the sample size had increased 1,528, mostly through the addition of siblings of children who already qualified for the sample. A few people were eliminated from the study after the initial volume was published because their test scores ". .. were deemed questionable" (Terman \& Oden, 1947, p. 7). Terman sorted his sample in different ways before settling on the classification reported in the second follow-up volume (Terman \& Oden, 1947, p. 7), which almost exactly matches the raw data (Terman et al., 19221991, Variable B001). According to the counts in the raw data, these groups were:

1. The "main experimental group," most of whom were identified through the research team's canvassing of California schools in urban areas (mostly Los Angeles and the San Francisco Bay area): 661 subjects.

2. The "outside Binet cases," which were children identified with the Stanford-Binet test but not through the canvassing. These totaled 365 children. Of these, 128 were identified before the beginning of the Genetic Studies of Genius in earlier studies of intelligence and intelligence testing (Burks et al., 1930, pp. 14-15).

3. The "outside group cases" were subjects that were identified through tests other than the Stanford-Binet that were administered by volunteers: 444 children. 
4. Siblings of children who were already selected for the Genetic Studies of Genius: 58 children. The siblings were added during the 1927-1928 follow-up and were usually too young to take an intelligence test in the earlier years of the study.

Although Terman lumped these groups together as "gifted" children in the study, sampling differences among these groups have some important implications. First, only the main experimental group resembles a probability sample. The canvassing that Terman's research assistants undertook is described in detail in the first volume of the Genetic Studies of Genius (Terman, 1926, pp. 21-34). Terman estimates that his team screened 168,000 children for inclusion in the study through the canvassing process. However, this does not mean that his research assistants gave 168,000 intelligence tests. At the time, most intelligence tests were individually administered, and giving tests to all children was prohibitively time consuming. Instead, in most schools, teachers were asked for their opinions of the smartest students in their class and the youngest students in their class. These students (typically 6-8\% of the entire school population) were then given a brief written test, and those that scored high enough were then individually administered an abbreviated version of the Stanford-Binet intelligence test. Finally, children who scored at or above a threshold of 120 or 130 (depending on the child's age) on the abbreviated tests received a full Stanford-Binet (Terman, 1916) to determine whether their IQ was high enough for inclusion in the study. However, younger (below age 7 or 8 ) and older children (in the high school grades) were usually administered other intelligence tests that were more age appropriate. There were also frequent departures from this general outline of procedures to accommodate local characteristics, especially for schools outside of the urban areas of California. 
The selection of the teacher's opinion of the smartest children is understandable, but the choice to test the youngest children in the class may seem perplexing to a 21 st century audience. However, previous research (Burt, 1917; Cuneo \& Terman, 1918; Madsen, 1920; Madsen \& Sylvester, 1919; Terman et al., 1915) had shown that often the youngest children in a classroom had the highest IQ scores. This was because grade skipping was much more common at the time than they are today, and often very young students had the highest IQs in a classroom because they were advanced compared to their age peers, though were typical when compared to their classroom peers. The phenomenon of the youngest children in a classroom having the highest IQs still occurs where grade levels are not strictly organized by age (e.g., Husain et al., 2019).

It is also important to note that the 58 siblings mentioned above under-represent the total number of sibling groups in the study. Some siblings were independently identified through the canvass or in the two outside case groups. The earlier volumes report other siblings (e.g., Burks et al., 1930, p. 29), but these siblings were added to the other groups-including the main experimental group. Therefore, there are individuals in the main experimental group who were not part of the canvass that was the principal means of identifying subjects for the longitudinal study.

Second, different groups did not always use the same tests, and minimum IQs were not consistent across groups or among subjects within a group. Generally, the minimum cutoff for inclusion in the study was 140. But siblings and "special cases" that interested the researchers were admitted to the Genetic Studies of Genius if they had an IQ of at least 135.

Less obvious is the varying minimum levels of intelligence needed to reach an IQ of 140. At the time of the study, IQ scores were calculated using the deviation score IQ formula:

$$
I Q=\frac{\text { mental age }}{\text { chronological age }} \times 100 \quad(\text { Formula } 1)
$$


The problem with this formula is that IQ scores are not directly comparable across age groups because the standard deviation varies from age to age. As a result, age groups with a larger standard deviation had to be less elite than age groups with a smaller standard deviation. Correcting for this artifact would require converting IQ scores to a within-age $z$-score to form a common scale (as modern deviation IQ scores are calculated.) However, Terman did not perform this correction. As a result, the 140 minimum IQ (or 135 for siblings and "special cases") has an inconsistent meaning across different age groups.

Another complication from the heterogeneity of the sample's age was that the 1916 Stanford-Binet underestimated the IQs of older gifted children. To compensate for this, Terman's team applied a statistical correction (described in Terman, 1926, pp. 41-45) that estimated the child's mental age on the test if it had a higher ceiling. The basis of this correction was the child's level of decreasing performance on existing subtests as the subtests grew more difficult.

Another source of heterogeneity in the minimum score needed for children to be selected in the study was errors in scoring the 1916 Stanford-Binet. There were 42 children $(2.7 \%$ of the entire sample, or $3.9 \%$ of the 1,068 children who took the Stanford-Binet initially) that were found many years later to have IQs below 135. The original IQs for these erroneously admitted individuals were as low as 116 (for uncorrected IQs) or 106 (for corrected IQs).

Unfortunately, the publicly available documentation does not describe how each individual sample member was selected for the study, nor the standard deviation of a norm sample for their age group. As a result, how the variation in the selection process and the degree to which a person's IQ was above average is unclear for sample members. What is clear, though, is that Terman's sample members were generally smarter than average, as was apparent in the way most excelled in academics as children and college students (among those who attended). 
As adults, they would also perform better than average in their careers (especially men) and live longer than average (Holahan \& Sears, 1995). However, their substantial contributions do not impress skeptics of the study, who claim that missing two future Nobelists demonstrates that the subjects of the Genetic Studies of Genius were not intellectual outliers (e.g., Gladwell, 2008).

These facts are important for formulating the simulation study which will be detailed below. The convoluted sampling and mix of probability sampling procedures and nonprobability sampling procedures means that a perfectly faithful simulation of Terman's sampling process is not possible. Nevertheless, we believe that we can answer our research questions by creating a simplified simulation based on plausible conditions and Terman's goals in selecting the absolute brightest children (as operationalized by a high IQ score). This will lead us to determine whether a similar design and goal would likely identify children who would later earn a Nobel Prize.

\section{Methods}

To estimate the likelihood that Terman would have identified one or both future Nobelists for his study, we conducted a simulation study based on realistic characteristics of the data and population. Because of inconsistent selection procedures, varying minimum levels of intelligence to be included in the study, and some non-probability sampling, it is impossible to perfectly simulate Terman's procedures. However, with some realistic assumptions, we can generate a range of plausible models of the selection procedures and estimate Terman's probability of selecting Shockley and/or Alvarez for inclusion in the Genetic Studies of Genius.

This simulation study (with 1,000 replications per set of conditions) examines the impact of three parameters' effects on the likelihood of correctly identifying future Nobelists in a simulation of the Genetic Studies of Genius. These three parameters include the following: (a) 5 
levels of measurement error for the intelligence test scores used to identify subjects, (b) 6 possible correlations between IQ and the likelihood of winning a Nobel Prize, and (c) 11 different thresholds of minimum IQ to win a Nobel Prize. Therefore, we have 330 (5 x 6 x 11) different combinations of conditions that could influence the likelihood of correctly identifying future Nobelists based on IQ. Each of these parameters are discussed further below. For each combination of conditions, we created a theoretical population of 168,000 students' IQ scores and flagged the top 1,528 students as those that would have been selected for the longitudinal study.

\section{Observed IQ}

First, we assigned each student a latent IQ. This latent IQ was randomly generated from a normal distribution on a standard normal scale with a mean of zero and standard deviation of one. This means that a latent IQ score of 0 in this study is equivalent to an IQ score of 100 on the Stanford-Binet IQ test, and a score of 1 is equivalent to an IQ score of about 115. Second, we assigned an error term to the latent IQ score to produce an observed IQ score, which is used to flag the top 1,528 students that would be included in the longitudinal study.

Measurement error values. To identify the realistic levels of measurement error in IQ scores at the time, we conducted a basic reliability generalization of 1916 Stanford-Binet intelligence test scores. A reliability generalization is a meta-analytic procedure that combines reliability coefficients - instead of effect sizes — to identify an average level of reliability (Vacha-Haase, 1998). We conducted a search of Google Scholar for all articles that mentioned "Stanford-Binet" in the text and were published between 1916 and 1936 (the year before the revised version of the Stanford-Binet was published). We identified 48 samples that reported test-retest reliability correlations in a total of 5,019 examinees. These individuals were tested an 
average of 23.57 months apart $(\mathrm{SD}=18.77$ months). We also identified 11 samples totaling 615 examinees with split-half correlations reported. The two types of reliability data were analyzed separately because reliability coefficients are not interchangeable (Henson \& Thompson, 2002), and it is best practice in a reliability generalization to not combine different types of reliability data (Beretvas \& Pastor, 2003). Both types of reliability data are valuable because they provide information about different sources of error. Test-retest correlations provide information about IQ score stability over time — an important issue because the IQ scores for potential longitudinal study members were collected in childhood, but their life outcomes occurred in adulthood. The split-half reliability coefficients were important because this captures internal consistency reliability information and error arising from test structure and item-level error.

For test-retest reliability, we collected information on the (a) correlation between the two test scores, (b) interval between the two testings, and (c) sample size. For split-half reliability, we only collected the reported correlation and whether it was corrected with the Spearman-Brown prophecy formula (Brown, 1910; Spearman, 1910). We used the Spearman-Brown prophecy formula to correct split-half values that were not corrected by the original researchers. Because both types of reliability reported were correlations, we used Fisher's $r$-to- $z$ transformation on the data prior to calculating an average that was weighted by sample size. We then converted the weighted average back to a correlation value.

In our examination of split-half reliability, we identified an outlier value. Madsen (1934, p. 268) reported a sample of 21 fifth graders who had a split-half reliability correlation of $r=-$ .009 , which was extremely unusual. (The second lowest split-half reliability value was $r=.57$ for 23 sixth graders in the same study.) Therefore, we report reliability estimates for all samples combined, and for the data with this outlier sample removed. 
For test-rest reliability values, we found that the average correlation was $r=.822(\mathrm{SD}=$ $.288,95 \% \mathrm{CI}=[.523, .940])$. We used the samples' average time interval between examinations and the square of the time interval as predictors to project the estimated reliability across a long time span. At one-year intervals, we found that the test-retest correlation was expected to reach a low of $r=.726$ at 5 years between testings before increasing again. We did not believe an increasing correlation as the time between testings increased was realistic, so we calculated a Loess regression, which showed the correlation leveling off at approximately $r=.75$ at five years. This is similar to Deary, Whiteman, et al.'s (2004) and Deary, Pattie, and Starr's (2013) test-retest correlations of $r=.67$ to .73 from ages 11 to $77-90$ (after correction for restriction of range; uncorrected $r \mathrm{~s}=.54$ to .66$)$.

The average split-half reliability was $r=.821(\mathrm{SD}=.260,95 \% \mathrm{CI}=[.565, .933])$. With the negative reliability value from the Madsen (1934) study removed, the new split-half average reliability became $r=.834(\mathrm{SD}=.199,95 \% \mathrm{CI}=[.668, .921])$.

Although test-retest and split-half reliability coefficients measure different sources of measurement error, they operate in a cumulative fashion to introduce error into the relationship between childhood IQ and adult accomplishment. Given the surviving data, it is not possible to know the total cumulative error of IQ scores in the early 20th century because different sources of error are not additive. For example, internal consistency reliability can be a source of the longitudinal instability over time because error in initial scores and later scores may attenuate the correlation between the two. However, understanding the degree to which different sources of error accumulate or are redundant with one another requires a generalizability theory study. But the necessary data were not collected to estimate total cumulative error for any groups of 1916 Stanford-Binet examinees because the generalizability theory methodology would not be 
invented until the 1970s. (Coincidentally, this methodology was invented by a sample member of the Genetic Studies of Genius: Lee Cronbach.) Therefore, we made educated guesses for a range of measurement error estimates as conditions in our simulation and allowed the amount of measurement error in our simulation to vary from .10 to .30 on a standardized scale. This corresponds to a total reliability of .70 to .90 . We chose the lower bound of reliability (i.e., error of .30) because it reflected the test-retest reliability at 5 years with some additional measurement error and the upper bound of reliability (i.e., measurement error of .10) because this would indicate a highly optimistic scenario.

\section{Association Between IQ and Nobel Laureate Status}

We then created a parameter that represents the strength of association between a student's intelligence and their likelihood of winning a Nobel Prize. Because that correlation between the two variables is unknown, we allowed it to vary across a wide range of values. At one extreme, we set this correlation to be zero; this would correspond to a scenario where either (a) restriction of range in IQ reduced the correlation to zero; (b) IQ serves as a threshold variable, and above a certain threshold the probability of earning a Nobel Prize does not increase; or (c) in the general population, earning a Nobel is uncorrelated with IQ. Each of these scenarios is plausible for various reasons. For example, scenario (a) is possible if scientists have a range of intelligence sufficiently narrow that there is little or no variation in IQ among them, thereby greatly weakening relationships between variables. Simonton (1976) argued in favor of scenario (b) and stated that above an IQ of 120 there are no additional benefits for individuals. Scenario (c) is possible because variables with extremely low base rates also have extremely low variation and often have correlations close to zero. At the other extreme, we set the relationship between intelligence and winning a Nobel Prize at 0.5, which we thought was the maximum plausible 
value for this parameter. Recent work on large, highly intelligent samples of people has strongly suggested that IQ does not function as a threshold variable and that high creative achievement in one's work increases monotonically throughout the IQ scale (e.g., Kell et al., 2013; Lubinski, 2009; Makel et al., 2016; Warne, in press, Chapter 25). The .50 value is conceptually similar to the correlation between IQ and school grades in a recent meta-analysis $(r=.54$; Roth et al., 2015). Given how much more grades are in control of a person than earning a Nobel prize is, we thought any statistical relationship higher than a correlation of $r=.54$ was definitely unrealistic.

This parameter, which we called $\rho_{I Q \cdot N o b e l}$, was used to create a variable that determined the propensity of receiving a Nobel as a function of an individual's intelligence, which we called Latent IQ to distinguish it from the observed IQ that is tainted with measurement error. We modeled this relationship with a logistic regression approach where we create probabilities of achieving a Nobel Prize as a function of the covariate Latent IQ score multiplied by $\rho_{I Q \cdot N o b e l}$ and then adding a randomized error term to capture other unmeasured factors that determine whether an individual wins a Nobel Prize:

$$
\ln \left(p(y) /(1-p(y))=\left(\rho_{\text {IQ }} \text { Nobel }\right)\left(\text { Latent }_{-} I Q_{i}\right)+\varepsilon_{i} \quad(\text { Formula } 2)\right.
$$

Where the $p(y)$ is the probability of winning a Nobel Prize, $\rho_{I Q \cdot N o b e l}$ term varied from 0.0 to 0.5 by increments of 0.1 . The $\varepsilon_{i}$ term in the equation above was also randomly generated, but had a fixed mean of 0 and standard deviation of 1 . This $\varepsilon_{i}$ term represents all non-IQ influences on a person's propensity of winning a Nobel Prize and is our recognition that a simple IQ-based model is underspecified.

\section{Threshold}

Lastly, we simulated thresholds that we believed reflect reasonable minimum observed IQs of Nobelists. Again, the absolute minimum observed IQ necessary to earn a Nobel Prize is 
unknown. However, we do know that Shockley earned IQ scores of 125 and 129 in his childhood (Shurkin, 2006, p. 13), so the absolute minimum must be no more than 125 . We arbitrarily chose to simulate a range of minimum IQs ranging from $z=1.3$ (equivalent to an IQ score of 119.5) to $z=2.3$ (IQ of 134.5), in increments of 0.1 standard deviations (i.e., 1.5 IQ points). An IQ of 119.5 is at the 90th percentile of intelligence, which is equal to a score Shockley obtained in adulthood (Shurkin, 2006), and we thought it was unlikely that people outside of the top $10 \%$ of intelligence would be eligible for a Nobel Prize in physics. The increments of 0.1 were chosen arbitrarily to give a fine level of detail in the changes in the dependent variable as the minimum Nobelist IQ threshold increased.

It is important to note that we did not examine the varying thresholds for admission into the Terman study. One reason is that Terman intended to only ever study about $1 \%$ of the population - people whom he thought would grow up to become a "genius" in adulthood. Lowering the threshold would have violated the goal of his longitudinal study. Moreover, Terman's funds were finite, and altering greatly the number of gifted children in his study would not have been feasible. Theoretical and practical goals constrained him and limited the possible minimum values of IQ to be selected for his study.

\section{Simulation}

In this simulation, we first created latent IQs for 168,000 students and then added the reliability error terms (five different conditions) to create the observed IQ. We then identified individuals in the simulated population who would be selected for the longitudinal study by selecting the top 1,528 students with the highest observed IQs.

To identify the future Nobelists in the simulated population, we used the latent IQ and $\rho_{\text {IQ Nobel }}$ terms to create a variable for all population members representing the likelihood of 
winning the Nobel Prize. We then calculated the mean and standard deviation of the latent IQ variable and eliminated any population members below the minimum Nobelist IQ threshold. Among the remaining population members, the two with the highest probability of earning a Nobel Prize (based on Formula 2) were identified as the future Nobelists.

This process was repeated 1,000 times for each of the 330 combinations of conditions. We then determined in each simulation whether one or both future Nobelists were also in the group 1,528 individuals with the highest observed IQs. We tallied the number and percentage of simulations in each combination of conditions in which zero, one, or two future Nobelists were also in the group selected for the longitudinal study.

\section{Results}

To best estimate whether Terman could have identified one or both future Nobelists with his sampling method, we conducted a simulation based on probable characteristics of the population and data Terman likely gathered. The results of the simulation indicated that there was a relatively low probability of identifying both Nobelists under the conditions simulated. Table 1 shows the descriptive statistics of simulations in selecting zero, one, or two Nobelists for the longitudinal study. Therefore, the simulation identified zero Nobelists in an average of $36.27 \%$ of samples, one Nobelist in an average of $41.05 \%$ of samples, and both Nobelists in an average of $22.7 \%$ of samples. The mean and the median are similar, which indicates a nearly symmetric distribution.

\section{Regression analysis results}

In order to better understand the relative importance of the parameters in predicting the probability of selecting zero, one, or two Nobelists for the simulation study, we conducted a 
regression analysis on each outcome (i.e., selecting zero Nobelists, selecting one Nobelist, and selecting two Nobelists). The general equation used for each outcome is

$$
Y_{i}=\beta_{1} M E_{i}+\beta_{2}\left(\rho_{\text {IQ }} \cdot \text { Nobel }\right)_{i}+\beta_{3} \text { Threshold }_{i}+\lambda_{i} \quad(\text { Formula 3) }
$$

where $Y_{i}$ is the proportion of the 1,000 iterations in the combination of conditions that selected the corresponding number of Nobelists for the longitudinal study, $M E$ is the measurement error that occurs when estimating latent IQ through observed IQ, $\rho_{I Q \cdot \text { Nobel }}$ is the parameter that represents the strength of correlation observed IQ and earning a Nobel Prize, Threshold is the varying minimum observed IQ needed to earn a Nobel Prize in the simulations, and $\lambda_{i}$ represents model error.

Table 2 shows that we conducted three regression analysis: one for each outcome. In the first model, where the outcome is the probability of selecting zero future Nobelists for the longitudinal study, the Threshold $(b=-0.582, p<0.001, \beta=-0.839)$ parameter had the strongest effect on identifying zero Nobelists. The $\rho_{\text {IQ }}$ Nobel $(b=-0.609, p<0.001, \beta=-0.475)$ parameter had the second strongest effect, while the $M E$ influence $(b=0.191, p<0.001, \beta=0.062)$ was weakest. In the second model, the outcome is the probability of selecting just one of the future Nobelists for the longitudinal study. The parameter for $\rho_{I Q} \cdot$ Nobel $(b=0.214, p<0.001, \beta=0.408)$ had the strongest effect on identifying one Nobelist, and Threshold $(b=0.083, p<0.001, \beta=$ $0.293)$ had the second largest effect. $M E(b=0.089, p=0.144, \beta=0.07)$ was not statistically significant, despite the large number of iterations in the simulation.

The outcome in the third model is the probability of selecting two future Nobelists for the longitudinal study. Threshold $(b=0.499, p<0.001, \beta=0.842)$ was again the most influential parameter on identifying two Nobelists, while $\rho_{I Q \text { Nobel }}(b=0.396, p<0.001, \beta=0.36)$ had the 
second largest effect. The influence of $M E(b=-0.28, p<001, \beta=-0.106)$ was statistically significant, but had little effect.

As can be seen from the regression analysis, the threshold parameter was the most important variable for models in which zero or two Nobelists were selected for the longitudinal study, but the other parameters had little influence in these models. Most notably, the $\rho_{I Q} \cdot$ Nobel and threshold parameters had a moderate to strong negative impact on predicting zero Nobelists, but had a moderate to strong positive impact when predicting two Nobelists. This is expected because these two models are reciprocals of one another. The measurement error parameter had a miniscule effect on selecting future Nobelists for the longitudinal study in both models.

Figures 1-3 visually display the results of the analyses. Figure 1 shows that measurement error had little impact on whether Terman's sampling procedure could identify two Nobelists, though lower measurement error did correspond to slightly better success in selecting both Nobelists for the study. In Figure 2, the influence of the $\rho_{I Q \cdot N o b e l}$ parameter (i.e., the correlation between latent IQ and earning a Nobel) was a more powerful influence on the probability of finding at least one future Nobelist. This is unsurprising because it indicates that a stronger correlation results in a greater likelihood of selecting future Nobelists by identifying high-IQ children - in accordance with the literature on selecting outliers on the basis of a predictor variable (Dawis, 1996; Taylor \& Russell, 1939). Finally, Figure 3 shows that the threshold parameter is most important when using Terman's sampling procedure to identify both future Nobelists. This means that as the threshold for the minimum IQ to earn a Nobel increases, the probability of selecting both Nobelists for the longitudinal study also increases.

\section{Discussion}

\section{Terman's Low Probability of Identifying Future Nobelists}


The results of this simulation study show that - in a simplified version of Terman's actual sampling procedure - that the most important of the three independent variables was the minimum threshold of IQ scores of Nobelists. For this variable, a higher minimum IQ for Nobelists was associated with simulated samplings identifying one or both future Nobel Prize winners. The second strongest influence on whether the sampling procedure could identify Nobelists during childhood was the correlation between IQ and earning a Nobel Prize. Finally, the reliability of the observed IQ scores mattered little in determining how many Nobelists could be identified by the sampling procedures.

Although nobody will ever know Terman's exact probability of identifying one or both future Nobel Prize winners in the school population of California at the time, the simulation results can provide some realistic estimates. The reliability generalization data we reported show that the measurement error of the IQ measures was probably about .25 or greater, and Shockley's IQ scores of 125 and 129 as a child and adult IQ of 119 (and the IQs in the 120s reported for some other Nobelists_-see Root-Bernstein, 2015)—show that the minimum IQ of a Nobelist is probably between 1.3 and 1.6 standard deviations above the mean. Finally, the correlation between IQ and earning a Nobel Prize is not known, but there is low variation in the dependent variable of whether someone wins a Nobel Prize (only 2 out of 168,000 individuals did), which will greatly attenuate the correlation. A realistic correlation between IQ and winning a Nobel Prize is about $r=0$ to $r=.20$. Given these facts, we can use the results of the simulation study to estimate that Terman had a probability of $53.0 \%$ to $83.2 \%$ of selecting neither Shockley nor Alvarez for the Genetic Studies of Genius. The probability of selecting at least one future Nobelist was $16.2 \%$ to $39.7 \%$, and the probability of identifying both individuals was $0.6 \%$ to $7.3 \%$. 
Supporting these low estimated probabilities for identifying one or both Nobelists in the Terman study is evidence from similar studies where researchers sampled individuals who were identified as being highly gifted in their childhood or adolescence. Most notable is the Study of Mathematically Precocious Youth (SMPY), which began in the early 1970s and consists of a total of 5,311 adolescents in five cohorts identified mostly in their early adolescence (Lubinski \& Benbow, 2006). The least selective SMPY cohort consists of adolescents who scored in the 97th percentile or higher on a grade-level achievement test; the four other cohorts consist of individuals in the top $1 \%$, top $0.5 \%$, and top $0.01 \%$ of cognitive ability and graduate students in top-ranked American university STEM programs. Even among these cognitively elite individuals, none has won a Nobel Prize_-despite the larger sample size than what was found in Terman's study. Similarly, a follow-up study of 156 alumni of the Hunter College Elementary School in New York City, which used an IQ cutoff of 140 or higher for admission in the 1940s and 1950s reported that at midlife "... none of the members of the Hunter group has (yet) achieved the status of a revolutionary thinker" (Subotnik et al., 1989, p. 143).

Elite colleges are another environment with a large number of highly intelligent people. But even at the world's most prestigious universities, low base rates make selecting future Nobelists supremely difficult. A study of the number of Nobelists per capita among undergraduates at universities showed that even at elite universities so few students win a Nobel that the selection procedures for these universities is inefficient at identifying future Nobelists among their applicants. The highest base rate for Nobelists among all universities in the world is "only" 1 in 741 (at École Normale Supérieure in France). At the universities with the second and third highest base rates of Nobelists, there is "only" one Nobelist for every 1,493 students — at the California Institute of Technology — and 1 in 3,125 students - at Harvard University (Clynes, 
2016). The base rates are much lower at typical universities; Zuckerman (1977, p. 82) found that over half of American science Nobel laureates earned their bachelor's degree at just one of ten universities. Thus, only at the most elite universities in the world would a researcher have a high probability of selecting a future Nobelist in a sample of 1,528 individuals.

If identifying future Nobelists at elite universities would be unlikely, then doing so in the general K-12 school population of children would be even more difficult. Among children born between 1901 and 1916 and living in the United States in 1921, the rate of winning a Nobel Prize $^{1}$ was 1 in 627,728 . Given this extremely low base rate in the general population, most random samples of 168,000 children in the 1920 s would have no future Nobelists in them (let alone samples of 1,528 children). This is additional evidence that supports our belief in the low estimated probabilities for selecting one or both future Nobelists for the Genetic Studies of Genius.

\section{Possible Changes to Terman's Sampling Method}

Given these low probabilities for selecting future Nobelists for his study, there is the question of what Terman could have altered in his sampling procedure to increase his probabilities of identifying Alvarez and/or Shockley. Assuming that selecting individuals on the basis of IQ was the goal of the sampling procedure, the answer is: not much. The most important independent variable in our simulation - the minimum IQ of Nobelists — was out of his control, as was the second most important variable (i.e., the correlation between IQ and winning a

\footnotetext{
${ }^{1}$ We calculated this number by identifying the 52 unique Nobelists ( 15 in physics, 11 in chemistry, 15 in physiology or medicine, 2 in literature, 2 in peace, 6 in economics, and 1 in chemistry and peace) who born between 1901 and 1916 who lived in the United States by 1921 and who had not started their postsecondary education yet. We estimated the number of individuals in the United States in 1921 who were born between 1901 and 1916 on the basis of the 1920 Census's number of individuals between the ages of 7 to 20 , which was $28,564,716$. Because the span of birth years for the Terman study's initial participants was two years longer than the census's age span, we multiplied the census number by $(16 / 14)$ to produce an estimated number of children who were born in the 16-year time span between 1901 and 1916. This produced an estimate of 32,645,390.
} 
Nobel). He could have lowered the minimum IQ for selection into his study, but lowering it to 120 or 125 would have made the number of sample members increase by about tenfold. This would have been too large of a sample to study, given the resources available to Terman (and most psychologists today).

The reliability of the IQ scores was somewhat in Terman's control, but only because he devised the tests that he used to identify children for his study. The reliability generalization information shows that split-half reliability (an early form of internal consistency reliability) was already high by the standards of the day $(r=.821)$. Even if Terman could have reduced this measurement error, the larger source of score instability was test scores over time (as shown by the lower test-retest reliability value of $r=.726$ ), which was out of Terman's control. However, the results of our simulation show that raising reliability had a much weaker effect on the probability of selecting Nobelists for the study than the other independent variables; any improvements in reliability would have had a marginal impact of the probability of identifying at least one Nobelist for the Genetic Studies of Genius

\section{How to Identify Future Nobelists}

It is important to remember, though, that studying future Nobelists was not the goal of the Genetic Studies of Genius. But if someone did have that as their goal, it is clear that sampling solely on IQ is not a productive strategy. Ironically, intelligence research provides insight into what variables would have increased the likelihood of identifying future winners of the Nobel Prize.

First, cognitive abilities besides intelligence matter (Lubinski, 2004). Having an aboveaverage IQ was a necessary but not sufficient condition for Shockley and Alvarez to later earn the Nobel Prize. Data from SMPY have shown that the intraindividual strengths and weaknesses 
of less global abilities is an important determinant of career selection and success for high-IQ individuals. SMPY subjects with higher verbal abilities compared to their mathematics scores favored humanities careers, while individuals with higher math than verbal abilities favored science careers (Park et al., 2007). Researchers using a similar sample from Duke University’s Talent Identification Program (TIP) replicated these results (Makel et al., 2016). Similar results were apparent in the Project Talent data (Gohm et al., 1998; Wai et al., 2009, Appendix B), which is particularly important because this sample is more representative than the self-selected SMPY and TIP subjects. SMPY also showed that selecting on the basis of high spatial ability has particular importance for identifying people who can excel in engineering and the physical sciences (Kell et al., 2013; Wai et al., 2009; Webb et al., 2007).

Another way that SMPY has shown that cognitive abilities besides intelligence matter is that a member of the sample did earn a Fields Medal in adulthood (Lubinski \& Benbow, 2006; Muratori et al., 2006). This is the most prestigious award in mathematics and is equivalent in prestige to a Nobel Prize. The direct correspondence between how most SMPY sample members were identified (i.e., through high performance in adolescence on a mathematics test) and the area of eminence for the Fields Medalist (i.e., mathematics) shows that identifying future eminent achievers is probably most effective by selecting people on the basis of highly developed specific abilities required to excel in a particular field — and not high IQ per se.

Second, interests matter. As Lubinski, 2004, succinctly stated, "People do not select educational tracks and occupations randomly. They do so, at least in part, on the basis of stable features of their personality, which include specific abilities" (p. 103). Most college students who major in the sciences have a pre-existing interest in science years before they start college (Bernstein et al., 2019; McCabe et al., in press), and advanced courses in high school have little 
or no causal effect on building interest in these areas (Warne et al., 2019). High-ability individuals (who often have the intellectual capacity to perform competently in many different jobs) tend to choose careers that they are interested in (Webb et al., 2002), and there is a great deal of intraindividual variability in their level of interest across domains (Achter et al., 1996). Therefore, identifying children who later become prominent scientists requires selecting them on the basis of interests in science-in addition to abilities. Interests are also important in predicting future occupational eminence because eminence requires a willingness to invest hours into a career (Lubinski, 2004; McCabe et al., in press). Obtaining highly prestigious awards usually requires a passion and interest in one's work that makes a person willing to invest a great deal of extra time into their vocation.

A third issue is due to an inherent limitation of IQ scores: "The IQ is a valuable global measure of intellect. It tells us much overall, but not enough specifically" (Stanley, 1974, p. 7). This explains why Terman's sample excelled at general outcomes_adult socioeconomic status, job prestige, academic success, and life expectancy — compared to the general population. Making predictions about more specific outcomes requires measures of the specific abilities that are needed to obtain a particular outcome. For this reason, spatial and math ability scores are important for identifying adolescents who would later obtain high STEM outcomes in SMPY (Kell et al., 2013; Wai et al., 2009), and a global measure of intelligence would be less effective. Thus, the lack of specific information in IQ scores means that Terman's sampling procedure of selecting people solely on the basis of IQ was unlikely to make accurate predictions about specific outcomes. And winning a Nobel Prize in physics, as both Shockley and Alvarez did, is a very specific outcome. What is obvious with 21 st century hindsight, though, was not at all apparent in 1921 when Terman started selecting children for his longitudinal study. Additionally, 
among highly intelligent individuals, specific abilities might be more important in identifying future eminence in a particular domain than global IQ scores anyway. When tested with instruments with a high enough test ceiling, it is apparent that many gifted individuals have large intraindividual differences in their broad cognitive abilities (Achter et al., 1996; Lohman et al., 2008). This is likely a consequence of Spearman's (1927, pp. 217-221) law of diminishing returns, which is the phenomenon where $g$ explains less variance among cognitive test scores in samples with higher average IQ than in average or low-IQ samples. In more intelligent individuals, the correlations among cognitive test scores are weaker, which results in greater intraindividual discrepancies among scores for bright individuals (e.g., Tommasi et al., 2015).

Finally, a massive sample size would be necessary to identify even a single future Nobelist. Even among high-IQ individuals, Nobel prizes are rare events. Sampling at universities with the highest base rates of Nobelists among their students would increase the probability of identifying a future Nobelist. But even at most elite universities, a sample size much larger than 1,528 individuals would be necessary.

Given these requirements, it is unsurprising that Terman's study failed to identify Alvarez or Shockley as "geniuses.” The 1916 Stanford-Binet was a highly verbal test (Becker, 2003; Krugman, 1939), as were the other instruments used to select children for Terman's longitudinal study (mostly the National Intelligence Tests and the Army Alpha, both groupadministered tests requiring reading). There was no screening for mathematics ability/achievement, nor for spatial ability or interests, and a failure to measure this constellation of abilities would make selecting future eminent physicists much more difficult (Lubinski, 2004). Finally, Terman's sample size was too small to make identifying even one future Nobelist likely. Our simulation results and the general nature of intelligence make it unrealistic to expect Terman 
to select people who would later experience a specific outcome, especially one with a low base rate. This also demonstrates the value of using a wide variety of rare outcomes to validate measures of elite cognitive ability; even a well-designed study might not select enough individuals who later achieve a low base rate outcome. In contrast, when Park et al. (2007) examined many elite outcomes with SMPY data, they found a robust relationship between test scores in adolescence and several outcomes with low base rates.

\section{An Example of Selecting People who Later Experience a Low Base Rate Outcome}

There is a contrasting story that shows the importance of interests and specific abilities in selecting people from a population, some of whom would later obtain high achievements that have a low base rate. In early 1981, famed Broadway producer and director Harold Prince held open auditions for young people to act in the premiere production of Stephen Sondheim musical Merrily We Roll Along. He cast 28 young actors who were all between the ages of 16 and 25 . The play opened and closed in November 1981 after just 16 performances (Pogrebin, 2011; Price, 2016). Among that group of 28 actors, 4 would later be nominated for a Tony Award (Tonya Pinkins, Jason Alexander, Liz Callaway, and Lonny Price), and 2-Alexander and Pinkins_-would later win a Tony Award (the latter three times).

Even among professional stage actors, being nominated for or winning a Tony Award is an extremely rare event. And yet, this selection process still identified multiple people who experienced these outcomes. Neither Prince nor Terman intended to find young people who would later reach the heights of eminence in their fields. But Prince selected people who did, while Terman missed two. The difference in selection procedure is clear: Prince looked for specific skills_-singing, dancing, and acting — that are highly relevant to winning a Tony Award. Additionally, the self-selected group of auditioners was highly interested and motivated in the 
performing arts. In contrast, Terman did not select on specific abilities or interests in science and therefore failed to identify two future Nobel-winning physicists as "geniuses."

\section{Value in Estimating Success}

There is one nagging question that remains about the study: If base rates are so low and predicting who will earn a Nobel Prize is so difficult, why should one bother identifying future Nobelists anyway? One reason to identify the precursors of eminence in any field is to create programs and interventions that can build the same skills in others. Having more Nobel-like thinkers may be a boon for scientific progress; even if others cannot be trained to reach the level of scientific productivity and importance of Nobel prize winners, increasing the average level of scientific thinking in the population may still be beneficial. A second reason to identify future Nobelists would be to divert resources towards their education and work - an increase of science education and improve the return on investment that universities, foundations, and government entities spend on research grants, fellowships, etc.

\section{Limitations}

As with all simulation studies, it was impossible for us to model every variable and condition which could have impacted the outcome we investigated. A good example of this was the fact that we did not model the varying deviations above average that subjects at different ages needed to obtain in order to have an IQ of 140, nor the fact that some subjects were admitted to the study with IQs below that threshold. We failed to simulate these variables because not enough information is in the data to permit estimates of how much error or variability this injected into the sampling procedure. For example, we do not know the conditional probability of a child with an IQ of 135 being selected for Terman's study if they had a sibling with an IQ of 140 or above who was selected. 
Another limitation of the study was that it modeled probability sampling, but the actual sampling procedure in the Genetic Studies of Genius was a mix of probability and nonprobability sampling. For example, Fred Terman (Lewis Terman's son) and Robert Sears (the son of Terman's colleague) were both part of the group of sample members who were identified through earlier studies (see Terman, 1916, pp. 98-99, for descriptions of them as children), and Terman's daughter, Helen Terman, was a participant in the longitudinal study. Our simulation does not model the selection process of children who have an "inside track" to being part of the Genetic Studies of Genius. It is not clear how the inclusion of these sample members impacts the probability that a sample of 1,528 high-IQ children would include at least one future Nobelist.

Another limitation is the fact that this simulation only models the probability that Terman would have selected Alvarez and/or Shockley for his longitudinal study. This is valuable as a historical question and worthy of investigating in its own right, given the importance and influence of the Genetic Studies of Genius. But the results may not generalize for a few reasons. First, both Shockley and Alvarez received Nobel Prizes in physics; these results may not apply to Nobel Prizes in chemistry, literature, peace, physiology or medicine, or economics. The simulation is also not informative about identifying eminence in other fields. Some members of the Genetic Studies of Genius reached high levels of eminence in their fields, including psychology, the entertainment industry, and music (Warne, 2019). Discounting these people's contributions because there is no Nobel Prize in these fields is myopic and arbitrary. Second, the unique historical factors at work in California in the 20th century-with the birth of Silicon Valley and a heavy financial investment in higher education and technology — may have made fostered eminence in the Terman sample to a greater degree than in groups of bright children in other locations or time periods. 
Finally, this simulation shares a common limitation with all simulation studies: the results are only informative insomuch as the conditions selected for the simulation are realistic. We have endeavored to have realistic conditions for all three of our simulation variables, and we have tried to justify our conditions to our readers. However, whether any particular range of conditions is plausible is an inherently subjective judgment. Simulation studies are inevitably a product of the statistical models and the conditions used to generate the simulation. It is impossible to know for sure whether we have selected conditions that reflected the sample and population data in 1920s California when Terman selected the sample, but we believe that our conditions are the most plausible ones, given the information available about the study's sampling process.

\section{Conclusion}

In recent years, some commentators (e.g., Gladwell, 2008) have criticized Terman's longitudinal study for being a study of geniuses that missing two children who would later achieve the pinnacle of scientific success: a Nobel Prize. However, we show in our simulation study that, under plausible conditions, Terman's sampling procedure had a $53.0 \%$ to $83.2 \%$ probability of identifying neither future Nobelist in a population of 168,000 school children.

Moreover, we believe that the later literature on selection and eminence explains why Terman was unlikely to identify either future Nobelist. First, events with rare base rates are- by definition—difficult to predict (Dawis, 1996; Taylor \& Russell, 1939). Second, a general measure of ability is a poor predictor of specific outcomes (Stanley, 1974). Third, predicting specific outcomes accurately requires measuring specific abilities and interests that are closely related to obtaining the desired outcome. Terman did not select children for the Genetic Studies of Genius on the basis of mathematical ability, spatial ability, and science interest because he 
was not specifically looking for children who would later engage in careers in science. Fourth, the minimum IQ Terman set for selection into his longitudinal study was higher than the minimum IQ needed to later receive a Nobel Prize, which systematically limited the number of future Nobelists he could have identified.

In all this discussion about Shockley, Alvarez, and what Terman missed, it is also important to close with the successes of Terman's sample members. Although none won a Nobel Prize, there were several prominent scientists in the group, including two future presidents of the American Psychological Association (Robert Sears and Lee Cronbach ${ }^{2}$ ), physiologist Ancel Keys, television writer Jess Oppenheimer (creator of I Love Lucy), Oscar-nominated film director Edward Dmytryk (Leslie, 2000), and composer Henry Cowell (Minton, 1988). Another noteworthy member of the study, Fred Terman (Seagoe, 1975), was an electrical engineer and provost at Stanford University who was one of the founders of Silicon Valley. The ranks of the study's subjects also included many people who succeeded in their fields but whose names are not famous in the 21 st century. The men in the sample earned higher salaries than the general population, and over $95 \%$ were professionals and semi-professionals in their middle age (Warne $\&$ Liu, 2017). Both men and women in the study lived longer than the general population at the time (Holahan \& Sears, 1995). These findings are in line with later research that showed that intelligence correlates with a wide variety of life outcomes, including career eminence (Lubinski, 2004). Thus, the failure to identify two future Nobelists is not a fatal flaw of the study and in no way abrogates the use of intelligence tests to identify gifted children or to predict future occupational success.

\footnotetext{
${ }^{2}$ Both are listed among the 200 most eminent psychologists to ever live (Diener et al., 2014), and Cronbach was the 48th most eminent psychologist of the 20th century (Haggbloom et al., 2002). Among the top 10 articles published in the prestigious journal Psychological Bulletin in its first 88 years, Cronbach was a co-author or the sole author on four of the top ten most cited articles, and the only author of more than one of the ten articles (Sternberg, 1992).
} 
However, the tale of Shockley's and Alvarez's failure to qualify for the Genetic Studies of Genius is a reminder that eminence requires more than high intelligence (McCabe et al., in press). This also has implications for psychologists or educators who wish to engage in specific talent development. They should select children on the basis of specific variables (including noncognitive variables) that are strong predictors of high performance in the desired domain. There is no one variable that will identify children who later become prominent in any professional field; rather predictors are context-specific and sometimes may not rely greatly on IQ scores at all. 


\section{References}

Achter, J. A., Lubinski, D., \& Benbow, C. P. (1996). Multipotentiality among the intellectually gifted: "It was never there and already it's vanishing." Journal of Counseling Psychology, 43(1), 65-76. https://doi.org/10.1037/0022-0167.43.1.65

Becker, K. A. (2003). History of the Stanford-Binet intelligence scales: Content and psychometrics (Assessment Service Bulletin No. 1). Riverside Publishing. Retrieved from https://www.hmhco.com/ /media/sites/home/hmh-assessments/clinical/stanfordbinet/pdf/sb5_asb_1.pdf?la=en

Beretvas, S. N., \& Pastor, D. A. (2003). Using mixed-effects models in reliability generalization studies. Educational and Psychological Measurement, 63(1), 75-95. https://doi.org/10.1177/0013164402239318

Bond, M. (2014). The secret of success: Blood, or sweat and tears? New Scientist, 221(2959), 3034. https://doi.org/10.1016/S0262-4079(14)60488-7

Brown, W. (1910). Some experimental results in the correlation of mental abilities. British Journal of Psychology, 3(3), 296-322. https://doi.org/10.1111/j.2044-82951910.tb00207.x

Burks, B. S., Jensen, D. W., \& Terman, L. M. (1930). Genetic studies of genius: Vol. III. The promise of youth: Follow-up studies of a thousand gifted children. Stanford University Press.

Burt, C. (1917). The distribution and relations of educational abilities. P. S. King.

Clynes, T. (2016). Where Nobel winners get their start. Nature, 538(7624), 152. https://doi.org/10.1038/nature.2016.20757 
Cuneo, I., \& Terman, L. M. (1918). Stanford-Binet tests of 112 kindergarten children and 77 repeated tests. The Pedagogical Seminary, 25(4), 414-428. https://doi.org/10.1080/08919402.1918.10532615

Dawis, R. V. (1996). Vocational psychology, vocational adjustment, and the workforce: Some familiar and unanticipated consequences. Psychology, Public Policy, and Law, 2(2), 229248. https://doi.org/10.1037/1076-8971.2.2.229

Deary, I. J., Pattie, A., \& Starr, J. M. (2013). The stability of intelligence from age 11 to age 90 years: The Lothian Birth Cohort of 1921. Psychological Science, 24(12), 2361-2368. https://doi.org/10.1177/0956797613486487

Deary, I. J., Whiteman, M. C., Starr, J. M., Whalley, L. J., \& Fox, H. C. (2004). The impact of childhood intelligence on later life: Following up the Scottish Mental Surveys of 1932 and 1947. Journal of Personality and Social Psychology, 86(1), 130-147. https://doi.org/10.1037/0022-3514.86.1.130

Diener, E., Oishi, S., \& Park, J. (2014). An incomplete list of eminent psychologists of the modern era. Archives of Scientific Psychology, 2(1), 20-31. https://doi.org/10.1037/arc0000006

Friedman, H. S., \& Martin, L. R. (2011). The longevity project: Surprising discoveries for health and long life from the landmark eight-decade study. Hudson Street Press.

Gensowski, M. (2018). Personality, IQ, and lifetime earnings. Labour Economics, 51, 170-183. https://doi.org/10.1016/j.labeco.2017.12.004

Gladwell, M. (2008). Outliers: The story of success. Little, Brown and Company. 
Gohm, C. L., Humphreys, L. G., \& Yao, G. (1998). Underachievement among spatially gifted students. American Educational Research Journal, 35(3), 515-531. https://doi.org/10.3102/00028312035003515

Greenberg, L. (1955). A critique of classic methods of identifying gifted children. The School Review, 63(1), 25-30. http://dx.doi.org/10.2307/1083412

Haggbloom, S. J., Warnick, R., Warnick, J. E., Jones, V. K., Yarbrough, G. L., Russell, T. M., Borecky, C. M., McGahhey, R., Powell, I., John L., Beavers, J., \& Monte, E. (2002). The 100 most eminent psychologists of the 20th century. Review of General Psychology, 6, 139-152. https://doi.org/10.1037/1089-2680.6.2.139

Heilman, K. M. (2016). Jews, creativity and the genius of disobedience. Journal of Religion and Health, 55(1), 341-349. https://doi.org/10.1007/s10943-015-0139-x

Henson, R. K., \& Thompson, B. (2002). Characterizing measurement error in scores across studies: Some recommendations for conducting "reliability generalization" studies. Measurement and Evaluation in Counseling and Development, 35(2), 113-126. https://doi.org/10.1080/07481756.2002.12069054

Holahan, C. K., \& Sears, R. R. (1995). The gifted group in later maturity. University of Stanford Press.

Husain, N. I. A. E., Meisenberg, G., Becker, D., Bakhiet, S. F., Essa, Y. A. S., Lynn, R., \& A1 Julayghim, F. M. H. (2019). Intelligence, family income and parental education in the Sudan. Intelligence, 77, 101402. https://doi.org/10.1016/j.intell.2019.101402

Jones, S. (1980). Playboy interview: William Shockley. Playboy, 27, 69-102.

Kell, H. J., Lubinski, D., \& Benbow, C. P. (2013). Who rises to the top? Early indicators. Psychological Science, 24(5), 648-659. https://doi.org/10.1177/0956797612457784 
Kell, H. J., Lubinski, D., Benbow, C. P., \& Steiger, J. H. (2013). Creativity and technical innovation: Spatial ability's unique role. Psychological Science, 24(9), 1831-1836. https://doi.org/10.1177/0956797613478615

Krugman, M. (1939). Some impressions of the revised Stanford-Binet scale. Journal of Educational Psychology, 30(8), 594-603. https://doi.org/10.1037/h0055529

Leslie, M. (2000). The vexing legacy of Lewis Terman. Stanford Magazine. https://stanfordmag.org/contents/the-vexing-legacy-of-lewis-terman

Lohman, D. F., Gambrell, J., \& Lakin, J. (2008). The commonality of extreme discrepancies in the ability profiles of academically gifted students. Psychology Science Quarterly, 50(2), 269-282.

Lubinski, D. (2004). Introduction to the special section on cognitive abilities: 100 years after Spearman's (1904) "'General intelligence,' objectively determined and measured". Journal of Personality and Social Psychology, 86(1), 96-111. https://doi.org/10.1037/0022-3514.86.1.96

Lubinski, D. (2009). Exceptional cognitive ability: The phenotype. Behavioral Genetics, 39(4), 350-358. https://doi.org/10.1007/s10519-009-9273-0

Lubinski, D., \& Benbow, C. P. (2006). Study of Mathematically Precocious Youth after 35 years: Uncovering antecedents for the development of math-science expertise. Perspectives on Psychological Science, 1(4), 316-345. https://doi.org/10.1111/j.17456916.2006.00019.x

Madsen, I. N. (1920). High-school students' intelligence ratings according to the Army Alpha test. School \& Society, 11(271), 298-300. 
Madsen, I. N., \& Sylvester, R. H. (1919). High-school students' intelligence ratings according to the Army Alpha test. School \& Society, 10(249), 407-410.

Makel, M. C., Kell, H. J., Lubinski, D., Putallaz, M., \& Benbow, C. P. (2016). When lightning strikes twice: Profoundly gifted, profoundly accomplished. Psychological Science, 27(7), 1004-1018. https://doi.org/10.1177/0956797616644735

Martin, L. R., Friedman, H. S., \& Schwartz, J. E. (2007). Personality and mortality risk across the life span: The importance of conscientiousness as a biopsychosocial attribute. Health Psychology, 26(4), 428-436. https://doi.org/10.1037/0278-6133.26.4.428

McCabe, K. O., Lubinski, D., \& Benbow, C. P. (2020). Who shines most among the brightest?: A 25-year longitudinal study of elite STEM graduate students. Journal of Personality and Social Psychology, 119(2), 390-416. https://doi.org/10.1037/pspp0000239

Minton, H. L. (1988). Lewis M. Terman: Pioneer in psychological testing. New York University Press.

Muratori, M. C., Stanley, J. C., Ng, L., Ng, J., Gross, M. U. M., Tao, T., \& Tao, B. (2006). Insights from SMPY's greatest former child prodigies: Drs. Terence ("Terry") Tao and Lenhard (“Lenny") Ng reflect on their talent development. Gifted Child Quarterly, 50(4), 307-324. https://doi.org/10.1177/001698620605000404

Park, G., Lubinski, D., \& Benbow, C. P. (2007). Contrasting intellectual patterns predict creativity in the arts and sciences: Tracking intellectually precocious youth over 25 years. Psychological Science, 18(11), 948-952. https://doi.org/10.1111/j.14679280.2007.02007.x

Pogrebin, A. (2011). Showstopper [Kindle e-book]. 
Price, L. (Director). (2016). Best worst thing that ever could have happened [Film]. Abramorama.

Rinn, A. N., \& Bishop, J. (2015). Gifted adults: A systematic review and analysis of the literature. Gifted Child Quarterly, 59(4), 213-235. https://doi.org/10.1177/0016986215600795

Robinson, H. B. (1981). The uncommonly bright child. In M. Lewis \& L. A. Rosenblum (Eds.), The uncommon child: Genesis of behavior (pp. 57-81). Plenum.

Root-Bernstein, R. (2015). Arts and crafts as adjuncts to STEM education to foster creativity in gifted and talented students. Asia Pacific Education Review, 16(2), 203-212. https://doi.org/10.1007/s12564-015-9362-0

Roth, B., Becker, N., Romeyke, S., Schäfer, S., Domnick, F., \& Spinath, F. M. (2015). Intelligence and school grades: A meta-analysis. Intelligence, 53, 118-137. https://doi.org/10.1016/j.intell.2015.09.002

Rubenstein, L. D., Pierson, E. E., Wilczynski, S. M., \& Connolly, S. C. (2013). Fitting the high ability program to the needs of individuals with autism spectrum disorders. Psychology in the Schools, 50(9), 910-922. https://doi.org/10.1002/pits.21719

Seagoe, M. V. (1975). Terman and the gifted. William Kaufmann, Inc.

Shurkin, J. N. (1992). Terman's kids: The groundbreaking study of how the gifted grow up. Little, Brown and Company.

Shurkin, J. N. (2006). Broken genius: The rise and fall of William Shockley, creator of the electronic age. Macmillan. 
Simonton, D. K. (1976). Biographical determinants of achieved eminence: A multivariate approach to the Cox data. Journal of Personality and Social Psychology, 33, 218-226. https://doi.org/10.1037/0022-3514-33.2.218

Simonton, D. K. (2015). Collaborating creators still have personal psychologies [Review of The innovators: How a group of hackers, geniuses, and geeks created the digital revolution, by W. Isaacson]. The American Journal of Psychology, 128(3), 403-407. https://doi.org/10.5406/amerjpsyc.128.3.0403

Sorokin, P. A. (1956). Fads and foibles in modern sociology and related sciences. Henry Regency.

Spearman, C. (1910). Correlation calculated from faulty data. British Journal of Psychology, 3(3), 271-295. https://doi.org/10.111/j.2044-8295.1910.tb00206.x

Spearman, C. (1927). The abilities of man: Their nature and measurement. The Macmillan Company.

Stanley, J. C. (1974). Intellectual precocity. In J. C. Stanley, D. P. Keating, \& L. H. Fox (Eds.), Mathematical talent: Discovery, description, and development (pp. 1-22). Johns Hopkins University Press.

Sternberg, R. J. (1992). Psychological Bulletin's top 10 "hit parade." Psychological Bulletin, 112(3), 387-388. https://doi.org/10.1037/0033-2909.112.3.387

Subotnik, R. F., Karp, D. E., \& Morgan, E. R. (1989). High IQ children at midlife: An investigation into the generalizability of Terman's Genetic Studies of Genius. Roeper Review, 11(3), 139-144. https://doi.org/10.1080/02783198909553190 
Taylor, H. C., \& Russell, J. T. (1939). The relationship of validity coefficients to the practical effectiveness of tests in selection: Discussion and tables. Journal of Applied Psychology, 23(5), 565-578. https://doi.org/10.1037/h0057079

Terman, L. M. (1916). The measurement of intelligence: An explanation of and a complete guide for the use of the Stanford revision and extension of the Binet-Simon Intelligence Scale. Houghton Mifflin.

Terman, L. M. (1926). Genetic studies of genius: Vol. I. Mental and physical traits of a thousand gifted children (2nd ed.). Stanford University Press.

Terman, L. M., Lyman, G., Ordahl, G., Ordahl, L., Galbreath, N., \& Talbert, W. (1915). The Stanford revision of the Binet-Simon scale and some results from its application to 1000 non-selected children. Journal of Educational Psychology, 6(9), 551-562. https://doi.org/10.1037/h0075455

Terman, L. M., \& Oden, M. H. (1947). Genetic studies of genius: Vol. IV. The gifted child grows up: Twenty-five years' follow-up of a superior group. Stanford University Press.

Terman, L., et al. (1922-1991). Terman life-cycle study of children with high ability, 1922-1991. ICPSR08092-v33 Ann Arbor, MI: Inter-university Consortium for Political and Social Research. https://doi.org/10.3886/ICPR08092.ve

Tommasi, M., Pezzuti, L., Colom, R., Abad, F. J., Saggino, A., \& Orsini, A. (2015). Increased educational level is related with higher IQ scores but lower $g$-variance: Evidence from the standardization of the WAIS-R for Italy. Intelligence, 50, 68-74. https://doi.org/10.1016/j.intell.2015.02.005 
Vacha-Haase, T. (1998). Reliability generalization: Exploring variance in measurement error affecting score reliability across studies. Educational and Psychological Measurement, 58(1), 6-20. https://doi.org/10.1177/0013164498058001002

Wai, J., Lubinski, D., \& Benbow, C. P. (2009). Spatial ability for STEM domains: Aligning over 50 years of cumulative psychological knowledge solidifies its importance. Journal of Educational Psychology, 101(4), 817-835. https://doi.org/10.1037/a0016127

Warne, R. T. (2019). An evaluation (and vindication?) of Lewis Terman: What the father of gifted education can teach the 21st century. Gifted Child Quarterly, 63(1), 3-21. https://doi.org/10.1177/0016986218799433

Warne, R. T. (in press). In the know: Debunking 35 myths about human intelligence. Cambridge University Press.

Warne, R. T., \& Liu, J. K. (2017). Income differences among grade skippers and non-grade skippers across genders in the Terman sample, 1936-1976. Learning and Instruction, 47, 1-12. https://doi.org/10.1016/j.learninstruc.2016.10.004

Warne, R. T., Sonnert, G., \& Sadler, P. M. (2019). The relationship between Advanced Placement mathematics courses and students' STEM career interest. Educational Researcher, 48(2), 101-111. https://doi.org/10.3102/0013189x19825811

Webb, R. M., Lubinski, D., \& Benbow, C. P. (2002). Mathematically facile adolescents with math-science aspirations: New perspectives on their educational and vocational development. Journal of Educational Psychology, 94(4), 785-794. https://doi.org/10.1037/0022-0663.94.4.785 
Webb, R. M., Lubinski, D., \& Benbow, C. P. (2007). Spatial ability: A neglected dimension in talent searches for intellectually precocious youth. Journal of Educational Psychology, 99(2), 397-420. https://doi.org/10.1037/0022-0663.99.2.397

Winkler, D. L., \& Jolly, J. L. (2014). Lewis M. Terman: A misunderstood legacy (1877-1956). In A. Robinson \& J. L. Jolly (Eds.), A century of contributions to gifted education: Illuminating lives (pp. 64-78). Routledge.

Zuckerman, H. (1977). Scientific elite: Nobel laureates in the United States. Free Press. 
Table 1

Overall Percentage of Iterations that Selected Zero, One, or Two Nobelists for the Longitudinal Study

\begin{tabular}{lrrr}
\hline & \multicolumn{1}{c}{ Zero Nobelists } & One Nobelist & \multicolumn{1}{c}{ Two Nobelists } \\
\cline { 2 - 3 } Median & $33.65 \%$ & $43.85 \%$ & $17.50 \%$ \\
Mean & $36.27 \%$ & $41.05 \%$ & $22.70 \%$ \\
Standard Deviation & $21.95 \%$ & $0.90 \%$ & $18.78 \%$ \\
\hline
\end{tabular}


Table 2

Regression Results for Each Model

\begin{tabular}{|c|c|c|c|}
\hline Parameter & $b$ (standard error) & Standardized $\beta$ & $p$ \\
\hline & \multicolumn{3}{|c|}{ Zero Nobelists (adjusted $R^{2}=0.933$ ) } \\
\hline$M E$ & $0.191(0.044)$ & 0.062 & $<0.001$ \\
\hline$\rho_{I Q \cdot \text { Nobel }}$ & $-0.609(0.018)$ & -0.475 & $<0.001$ \\
\hline \multirow[t]{2}{*}{ Threshold } & $-0.582(0.010)$ & -0.839 & $<0.001$ \\
\hline & \multicolumn{3}{|c|}{ One Nobelists (adjusted $R^{2}=0.250$ ) } \\
\hline$M E$ & $0.089(0.060)$ & 0.070 & 0.144 \\
\hline$\rho_{\text {IQ. Nobel }}$ & $0.214(0.025)$ & 0.408 & $<0.001$ \\
\hline \multirow[t]{2}{*}{ Threshold } & $0.083(0.014)$ & 0.293 & $<0.001$ \\
\hline & \multicolumn{3}{|c|}{ Two Nobelists (adjusted $R^{2}=0.848$ ) } \\
\hline$M E$ & $-0.280(0.057)$ & -0.106 & $<0.001$ \\
\hline$\rho_{\text {IQ.Nobel }}$ & $0.396(0.024)$ & 0.360 & $<0.001$ \\
\hline Threshold & $0.499(0.013)$ & 0.842 & $<0.001$ \\
\hline
\end{tabular}

Note $. M E=$ measurement error. 


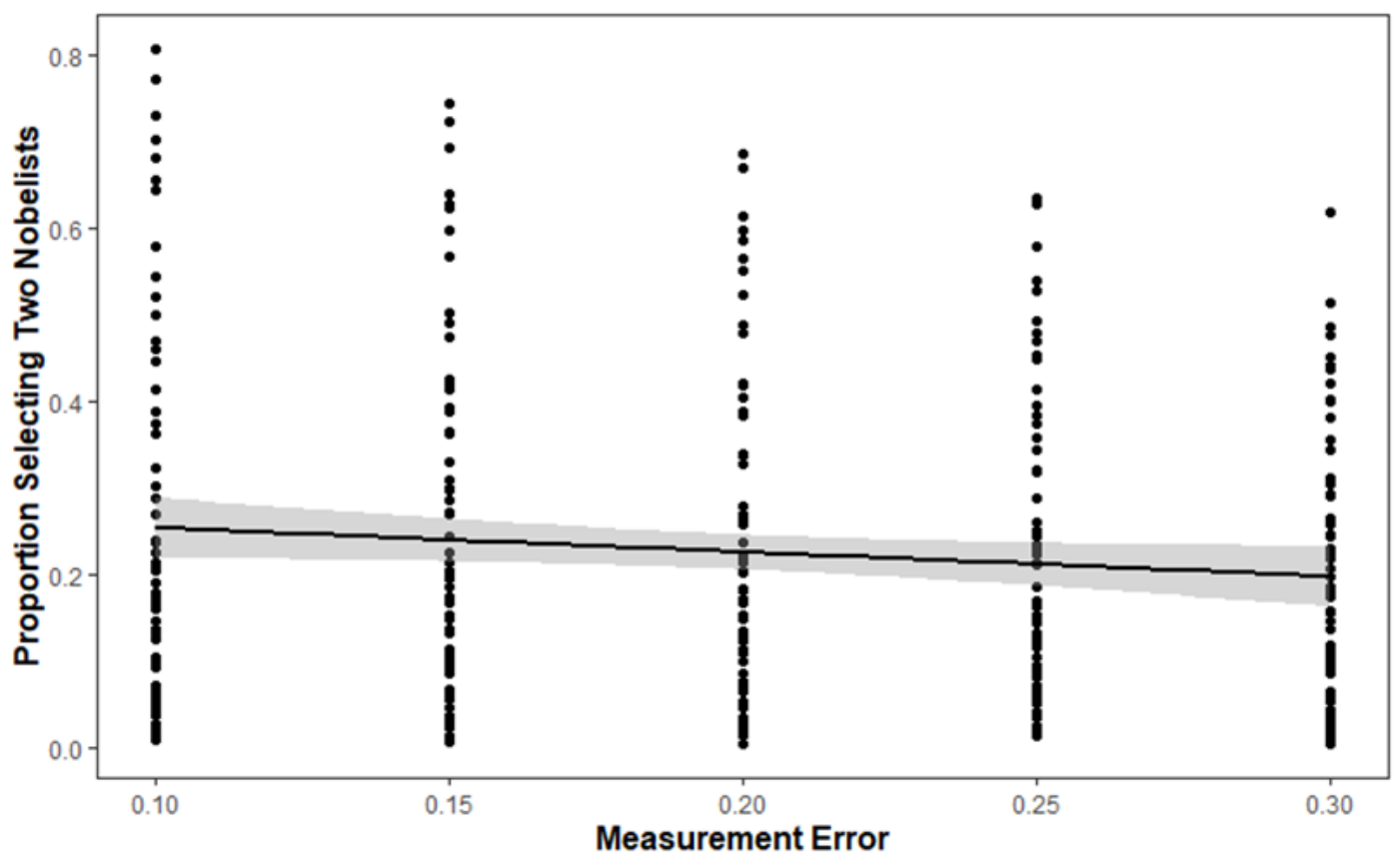

Figure 1. Regression Analysis of Measurement Error Parameter Predicting Two Nobelists 


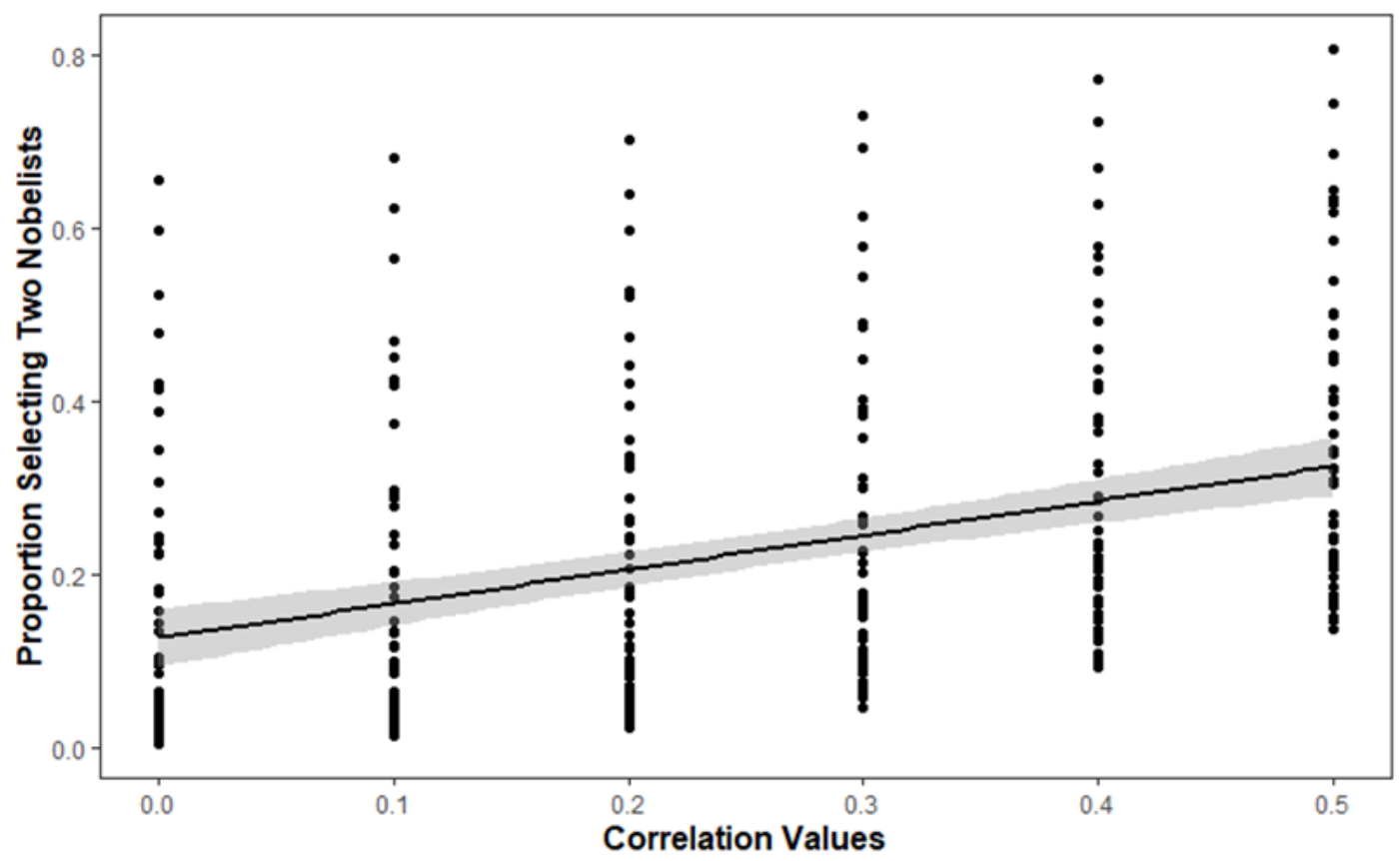

Figure 2. Regression Analysis of $\rho_{I Q \cdot N o b e l}$ Parameter Predicting Two Nobelists 


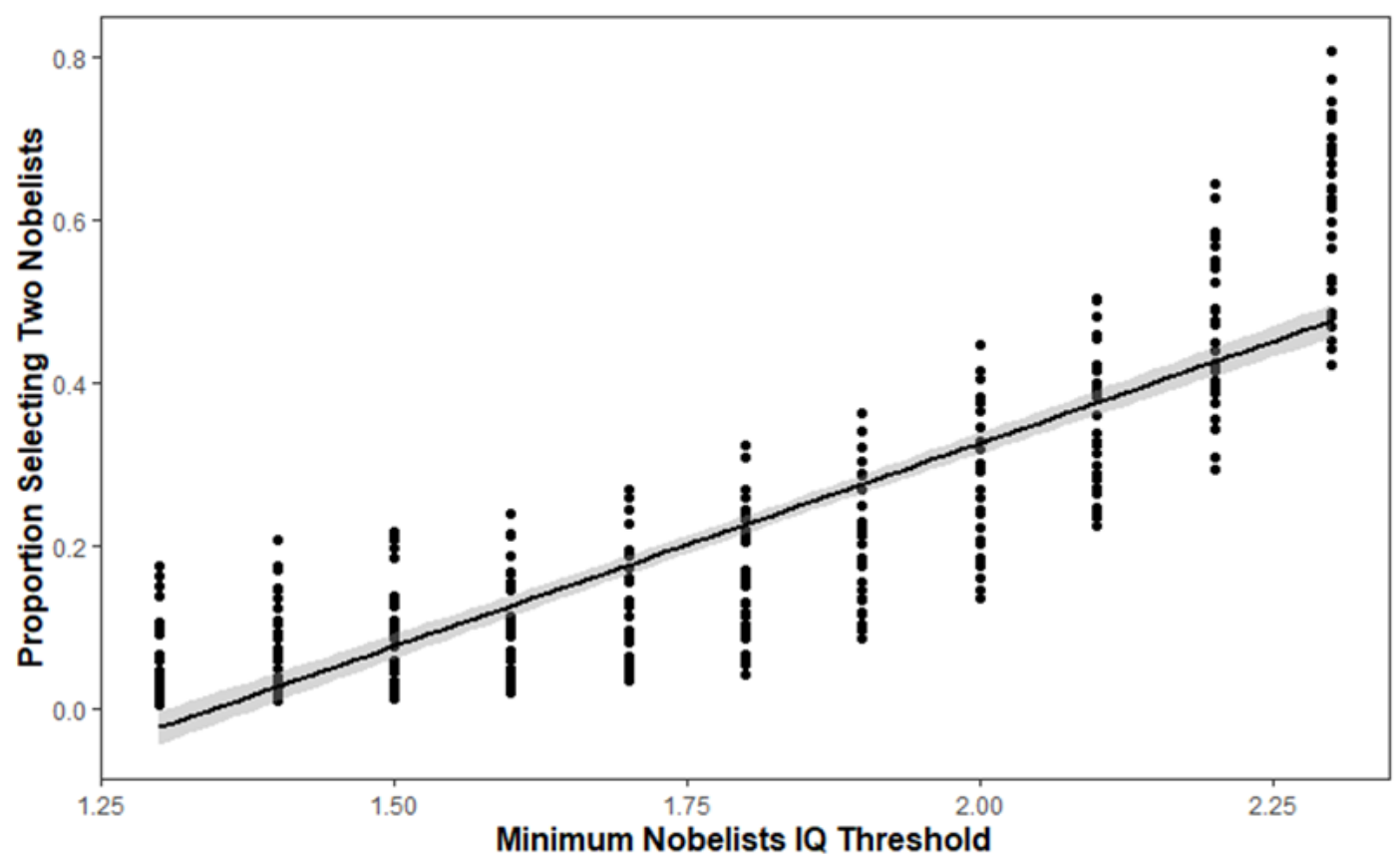

Figure 3. Logistic Regression Analysis of Threshold Parameter Predicting Two Nobelists 